\section{What is already known on this topic}

Epilepsy is associated with a wide range of markers of social and economic disadvantage

A small number of epidemiological studies have confirmed this association but have not established the direction of causality

\section{What this study adds}

The incidence of epilepsy, adjusted for age and sex, in the most deprived fifth of the study population was 2.3 times that in the least deprived fifth

Socioeconomic deprivation is an important risk factor for the development of epilepsy, though the results may partly reflect differences in incidence within and outside London

DCH, PW, and JWS wrote the manuscript. All authors reviewed and approved the final draft. JWS is guarantor.

Funding: Wellcome Trust, Brain Research Trust, the University College Hospital NHS Trust, National Society for Epilepsy. PW is funded by a Public Health Career Scientist Award.

Competing interests: None declared.

1 Rodin E. Vocational and educational problems with epileptic patients. Epilepsia 1972;13:149-60.

2 Jacoby A, Buck D, Baker G, McNamee P, Graham JS, Chadwick D. Uptake and costs of care for epilepsy: findings from a UK regional study. Epilepsia 1998;39:776-86.

3 Lisle JR, Waldron HA. Employees with epilepsy in the NHS. BMJ 1986;292:305-6.

4 Hart YM, Shorvon SD. The nature of epilepsy in the general population. I. Characteristics of patients receiving medication for epilepsy. Epilepsy Res 1995;21:43-9.

5 Sander JW, Shorvon SD. Epidemiology of the epilepsies. J Neurol Neurosurg Psychiatry 1996;61:433-43.

6 Morgan CLI, Ahmed Z, Kerr MP. Social deprivation and prevalence of epilepsy and associated health usage. J Neurol Neurosurg Psychiatry 2000;69:13-7.

7 Jacoby A, Baker GA, Steen N, Potts P, Chadwick DW. The clinical course of epilepsy and its psychosocial correlates: findings from a UK community study. Epilepsia 1996:37:148-61.

8 Shamansky SL, Glaser GH. Socioeconomic characteristics of childhood seizure disorders in the New Haven area: an epidemiologic study. Epilepsia 1979;20:457-74.

9 World Health Organization. Targets for all. Copenhagen: World Health Organization, 1985.

10 Department of Health. The new NHS: modern and dependable. London, Stationery Office, 1997.

11 MacDonald BK, Cockerell OC, Sander JW, Shorvon S. The incidence and lifetime prevalence of neurological disorders in a prospective community-based study in the UK. Brain 2000;123:665-76.

12 Carstairs V, Morris R. Deprivation and health in Scotland. Aberdeen: Aberdeen University Press, 1991

13 Acheson D, Barker D, Chambers J, Graham H, Marmot M, Whitehead M. Independent inquiry into inequalities in health: report. London: Stationery Office, 1998:1-164.

14 Nelson KB, Ellenberg JH. Predictors of epilepsy in children who have experienced febrile convulsions. N Engl J Med 1976;295:1029-33.

15 Haerer AF, Andreson DW. Prevalence and clinical features of epilepsy in a biracial United States population. Epilepsia 1986;27:66-75.

16 Wright J, Pickard N, Hakin N. A population-based study of prevalence, clinical characteristics and effect of ethnicity in epilepsy. Seizure 2000:9:309-13.

17 Annegers JF, Annegers JF, Risch N, Hauser WA, Susser M. Relations of genetic and environmental factors in the etiology of epilepsy. Ann Neurol 2001;39:442-9.

(Accepted 30 May 2002)

\title{
Detection of depression and anxiety in primary care: follow up study
}

\author{
David Kessler, Olive Bennewith, Glyn Lewis, Deborah Sharp
}

Division of Primary

Health Care,

University of

Bristol, Bristol

BS6 6JL

David Kessler

research fellow

Deborah Sharp

professor

Department of

Social Medicine,

University of

Bristol, Bristol

BS8 2PR

Olive Bennewith

research associate

Division of

Psychiatry,

University of

Bristol, Bristol

BS6 6JL

Glyn Lewis

professor

Correspondence to:

D Kessler

david.kessler@

bristol.ac.uk

BMJ 2002;325:1016-7
Research shows that general practitioners fail to diagnose up to half of cases of depression or anxiety. ${ }^{1}$ Many studies are cross sectional and have been criticised because, unlike primary care itself, they contain no longitudinal element. They do not always indicate whether undetected depression is important clinically or whether it is diagnosed at a later date, persists undetected, or causes disability.

We aimed to determine whether depression or anxiety not diagnosed during one general practice consultation is diagnosed during follow up or is self limiting and of no clinical importance.

\section{Participants, methods, and results}

We followed up consecutive attenders at a general practice in north Bristol in 1997. ${ }^{2}$ The original sample represented patients attending morning and evening surgeries and all doctors in the practice.

We interviewed 179 patients with the 12 item general health questionnaire and 12 item short form health survey. ${ }^{34}$ We followed up 71\% (160/227) of patients still in the practice and 43\% (28/65) of those who had moved. Patients who scored 3 or more on the general health questionnaire received a more detailed psychiatric assessment with the clinical interview schedule. $^{5}$ We analysed the general practitioners' records for psychological diagnoses, treatments, and referrals during the follow up period.

Patients who were followed up were older (48.5 v 43.3 years), were more likely to be female $(76 \%$ v $68 \%)$, and had lower mean scores on the general health questionnaire (3.6, 95\% confidence interval 3 to 4.1 , $v$ $4.2,3.5$ to 4.9$)$ than those we did not follow up (67 declined, 37 were untraceable, and nine questionnaires were incomplete). None of these differences was statistically significant. Overall, the results of the questionnaire showed that $88 / 179(49 \%, 42 \%$ to $57 \%)$ patients had depression or anxiety in the original study, but only $34(39 \%, 28 \%$ to $50 \%)$ of these had received a diagnosis of depression or anxiety at that time. Of the 54 who had not received a diagnosis during the original study, 22 received a diagnosis during the three years of follow up (figure).

Of the 56 patients who received a diagnosis, 38 $(68 \%, 54 \%$ to $80 \%)$ were treated with antidepressants. Twelve $(21 \%, 12 \%$ to $34 \%)$ were referred to psychiatric services.

Psychological diagnoses had never been made in 32 of the 88 patients; $16 / 88(18 \% ; 11 \%$ to $28 \%)$ 
patients had depression or anxiety according to the general health questionnaire and had never received a diagnosis from their general practitioner. These 16 patients had severe symptoms (mean score on general health questionnaire $6.4,4.8$ to 7.9 ). Twelve ( $14 \%, 7 \%$ to $23 \%$ ) of the 88 patients without a diagnosis were cases according to the clinical interview schedule or had daily activities adversely affected by anxiety or depression according to the short form health survey. ${ }^{45}$

\section{Comment}

Although many patients with depression did not receive a diagnosis at a single consultation, most were given a diagnosis at subsequent consultations or recovered without a general practitioner's diagnosis. Three years later, $14 \%$ of patients with depression still had a clinically severe condition, had not received a diagnosis, and might have benefited from treatment.

The prevalence of anxiety and depression (49\%) was in line with the high prevalence often found in primary care studies. ${ }^{1}$ We did not follow up 43 undiagnosed cases (of a total of 153 cases in the original study)-we do not know the outcome of these cases, but the patients were more likely to have changed practice than those we did follow up. This mobility means that those we did not follow up may have been less likely to have received appropriate diagnosis and treatment than those we did follow up. We may have underestimated the proportion of undetected cases.

This small study estimates hidden psychiatric morbidity more realistically than cross sectional studies. General practitioners feel they have been criticised unfairly for missing up to half of the patients with depression that present to them. This study supports their view. Undiagnosed depression may lead to long term disability, but the problem may not be as large as has been thought. Evidence that general practitioners fail to detect one in seven patients with treatable depression are more in tune with clinical impression than estimates of one in two, but the outcome for

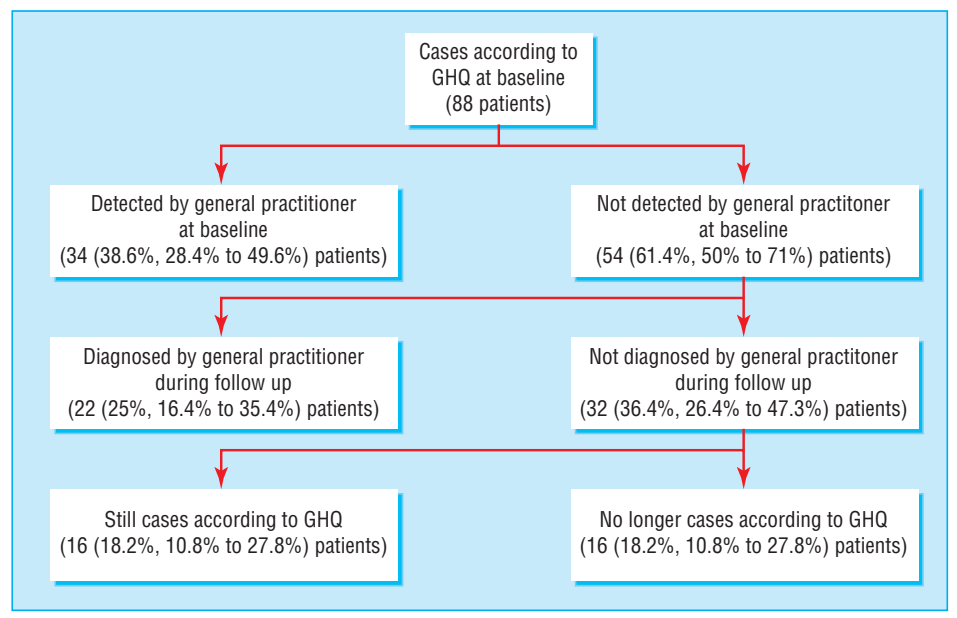

Diagnosis of patients with depression and anxiety in a cross sectional study and three year follow up period. $\mathrm{GHQ}=$ general health questionnaire

patients with undetected depression still needs attention.

Contributors: DK and GL had the idea for the current study and analysed the data. $\mathrm{OB}$ collected the data and helped with the analysis. The paper was written jointly by DK, GL, and DS. DK is the guarantor.

Funding: Small project grant from NHS South and West Research and Development. DK is an MIA/RCGP research fellow.

Competing interests: DS and DK received honorariums for attending two meetings sponsored by GlaxoSmithKline. GL has received payment from a number of pharmaceutical companies.

1 Goldberg D, Huxley P. Common mental disorders. London: Routledge, 1992 2 Kessler D, Lloyd K, Lewis G, Gray DPG, Heath I. Cross sectional study of symptom attribution and recognition of depression and anxiety in primary care. BMJ 1999;318:436-40.

3 Goldberg D, Williams P. A user's guide to the general health questionnaire. Windsor: NEFR Nelson, 1991.

4 Jenkinson C, Layte R. Development and testing of the UK SF-12.J Health Serv Res Policy 1997;1:14-8.

5 Lewis G, Pelosi A, Glover E. The development of a computerised assessment for minor psychiatric disorder. Psychol Med 1988:18:737-45. (Accepted 7 March 2002)

\section{How a rare diagnosis caused me to sprain my ankle}

My brain is the sort that is much better at retaining esoteric facts than more useful information. As a first year clinical student, I had been reading up tumour pathology and was fascinated by a description of chordomata, rare tumours that occur anywhere in the spinal tract from the midbrain to the cauda equina and that retain the cellular characteristics of the primitive notochord. Commonest at the lower end of the spinal tract, they were said to feel like a cricket ball attached to the front of the sacrum.

The next day, on a surgical ward round, my consultant asked me to examine an elderly man rectally. I did so and felt a cricket ball attached to the front of the sacrum. "What is the diagnosis?" I was asked.

"Chordoma, Sir," I replied.

"Nonsense," he said, "it's a carcinoma of rectum." I am not sure whether he had heard of the condition.

At surgery the next day the tumour was removed, and it did indeed prove to be a chordoma. I decided to write it up for the surgical prize and, reviewing the hospital records, discovered that there had only been one other case, some 30 years earlier. It had occurred in the midbrain, and the patient had been a distinguished scientist and FRS. Six months later, I was about to hand in my study when I heard that my original patient had been admitted in extremis. Sadly he died, but his autopsy report and cellular photographs did much to enhance my report.

A week later, tired by my exertions, I was walking with a friend along the South Downs when we noticed a typical downland church nestling in the valley and decided to visit it. We climbed down to the flint walled graveyard, and my friend walked round to the lychgate while I decided to climb over the wall. As I landed, I twisted my ankle on a grave kerbstone; it bore the name and epitaph of the distinguished scientist.

John Williams retired general practitioner

We welcome articles of up to 600 words on topics such as A memorable patient, A paper that changed my practice, My most unfortunate mistake, or any other piece conveying instruction, pathos, or humour. If possible the article should be supplied on a disk. Permission is needed from the patient or a relative if an identifiable patient is referred to. We also welcome contributions for "Endpieces," consisting of quotations of up to 80 words (but most are considerably shorter) from any source, ancient or modern, which have appealed to the reader. 